\title{
Paratransit: Introduction to the special section
}

\author{
David A. King a \\ Columbia University
}

Over the past few years, private taxi, jitneys, and other paratransit services have blossomed in cities around the world. Scholars have noticed. Two things stand out immediately. First, we don't know very much about how taxi and paratransit services affect travel behavior and mode choices. Second, we know even less about who uses these systems. Because these services tend to serve niche populations, it is difficult to assess who an "average" rider is. What we do know about taxi services and para-,transit is that they are important complements of - and occasional substitutes for-conventional fixed-route transit.

For decades people have argued that there is substantial promise to the idea that private transit systems can extend the reach of fixed-route public systems (Rosenbloom 1970; Kirby, Bhatt et al. 1974; Rosenbloom 1982; Cervero 1985). Yet arguments for expanding private or deregulated local transit services have been largely ignored. For years public transit providers and taxi operators have opposed expansion of services they view as competitors, but this only partially explains why private transit has been scarce in most cities in North America and Europe. Complaints of competition are not unfounded; since the invention of jitneys, they have succeeded by operating on popular transit routes (see Hodges (2006) for a description of the 1914 jitney fights in Los Angeles). Even though these services follow established transit, they are not perfect substitutes for public transit service, as New York City's attempt to replace canceled bus routes with commuter vans showed (King and Goldwyn 2014).

As public interest in paratransit waxes and wanes over time, we are currently in an era of excitement and activity in this area. Struggling public transit systems are looking for ways to improve their services and ridership but too often don't have the financial resources to do so. This suggests opportunities for paratransit services to work with transit agencies. New technologies — especially smart phonesgive operators and riders more data and convenience that makes transit run smoother. And it needs to be noted that many firms around the world have discovered there is money to be made providing these services.

This special section of the Journal of Transport and Land Use presents three articles in which the authors examine complementary travel modes to conventional public transit systems. Together these three papers provide evidence of how informal and nontraditional transit operates in conjunction with established transit services as well as competes with certain types of services. It is impossible to make generalized statements about whether taxis, paratransit, and informal buses compete with other modes of travel and formal transit.

In the United States, intercity bus travel is the fastest growing transit service (Schwieterman and Fischer 2010) and places new stress on local streets. These buses need places to pick up and drop off passengers, and frequently do so at whatever curb they can find. Nicholas Klein asked riders of these curbside buses about their travel preferences to help identify how the growth of new bus services may

adk2475@columbia.edu

Copyright 2015 David A. King

http://dx.doi.org/10.5198/jtlu.2015.823

ISSN: 1938-7849 | Licensed under the Creative Commons Attribution - NonCommercial License 3.0.

The Journal of Transport and Land Use is the official journal of the World Society for Transport and Land Use (WSTLUR) and is published and sponsored by the University of Minnesota Center for Transportation Studies. 
affect legacy bus services and intercity rail travel. He describes how new curbside bus riders substitute bus trips for other rail transit trips rather than driving trips, and how the low fares of curbside buses may lead to additional intercity trips taken. As this is a rapidly changing travel market more research is needed, but these initial results are provocative.

In another piece, Andreas Neumann and co-authors developed a simulation model to help plan for minibus service routes in South Africa. As minibuses are the second most popular form of motorized travel in the country, developing analytic methods for planning purposes is crucial. Lastly, Pablo Salazar Ferro and Roger Behrens examine how feeder buses extend trunk lines in transit networks. They argue that shifts to truck-and-feeder networks in Santiago and Bogota failed to meet their initial expectations, but with fuller inclusion of paratransit services - in particular the benefits of flexible routing and coverage areas - the promises of these services as complementary to fixed-route public transit can still be achieved.

\section{References}

Cervero, R. 1985. Deregulating urban transportation. Cato Journal 5(1): 219-238.

Ferro, P. S., and R. Behrens. 2015. From direct to trunk-and-feeder public transport services in the Urban South: Territorial implications. The Journal of Transport and Land Use 8(1): 123-136. Retrieved April 22, 2015, from http://jtlu.org.

Hodges, A. 2006. Roping the wild jitney: the jitney bus craze and the rise of urban autobus systems. Planning Perspectives 21(3): 253-276.

King, D. A. and E. Goldwyn. 2014. Why do regulated jitney services often fail? Evidence from the New York City group ride vehicle project. Transport Policy 35(0): 186-192.

Kirby, R. F., K. U. Bhatt, M. Kemp, R. McGillivray, and M. Wohl. 1974. Para-transit: Neglected Options For Urban Mobility. Washington, DC: Urban Institute.

Klein, N. J. 2015. Get on the (curbside) bus: The new intercity bus. The Journal of Transport and Land Use 8(1): 155-169. Retrieved April 22, 2015, from http://jtlu.org.

Neumann, A., D. Röder, and J. W. Joubert. 2015. Toward a simulation of minibuses in South Africa. The Journal of Transport and Land Use 8(1): 137-154. Retrieved April 22, 2015, from http://jtlu.org.

Rosenbloom, S. 1970. Taxis, jitneys \& poverty. Society 7(4): 47-54.

Rosenbloom, S. 1982. The planner's role in private transportation efforts. Transportation 11: 101-103.

Schwieterman, J. P. and L. Fischer. 2010. The Intercity Bus: America's Fastest Growing Transportation Mode: 2010 Update on Scheduled Bus Service. Chaddick Institute for Metropolitan Development, DePaul University. 